\title{
Organisational Factors of Occupational Accidents with Movement Disturbance (OAMD) and Prevention
}

\author{
Sylvie LECLERCQ ${ }^{1}$ \\ ${ }^{1}$ Working Life Department, INRS, France \\ Received April 4, 2014 and accepted July 30, 2014 \\ Published online in J-STAGE August 23, 2014
}

\begin{abstract}
Workplace design and upkeep, or human factors, are frequently advanced for explaining so-called Occupational Slip, Trip and Fall Accidents (OSTFAs). Despite scientific progress, these accidents, and more broadly Occupational Accidents with Movement Disturbance (OAMDs), are also commonly considered to be "simple". This paper aims to stimulate changes in such perceptions by focusing on organisational factors that often combine with other accident factors to cause movement disturbance and injury in work situations. These factors frequently lead to arbitration between production and safety, which involves implementation of controls by workers. These controls can lead to greater worker exposure to OAMD risk. We propose a model that focuses on such controls to account specifically for the need to confront production and safety logics within a company and to enhance the potential for appropriate prevention action. These are then integrated into the set of controls highlighted by work organisation model developed by the NIOSH.
\end{abstract}

Key words: Movement disturbance, Slip trip and fall, Organisational factor, Worker controls, Accident genesis

\section{Introduction}

Slips, Trips and Falls (STFs) lead recurrently to injuries in occupational situations ${ }^{1)}$. These accidents are triggered by a movement disturbance (a slip or a trip) when working, especially when walking. Other movement disturbances (a wrench slipping, an arm colliding with a wall, etc.) can occur in occupational situations; moreover, these can arise when performing different types of tasks (tightening a bolt, moving an item alone or with a colleague, etc.). This paper considers OSTFs and, more broadly, Occupational Accidents with Movement Disturbance (OAMDs); the

E-mail: sylvie.leclercq@inrs.fr

(C)2014 National Institute of Occupational Safety and Health latter composing a set of accidents operationally defined by Leclercq et al. ${ }^{2,3)}$, which involve a heavy cost in both human and financial terms ${ }^{4}$.

The literature often advances workplace design and upkeep $^{5,6)}$, access system configuration ${ }^{7)}$ or, again, human factors $^{8,9)}$ for explaining OSTFAs. Implementing actions that neutralise these factors to secure displacements, represents a first step towards preventing these accidents. However, such actions frequently overlook not only task diversity, but also production requirements and they can therefore only offer a partial response to preventing all OAMDs. Research into these accidents shows that, as in all occupational accidents, many accident-causing event configurations stem from arbitration between production and safety, which cannot be overlooked if progress is to be achieved in the prevention field. Production-safety arbitrations lead to controls applied under working conditions in 
order to perform the task while maintaining safety. Many of these controls are reflected in worker movements when performing the task. The control most frequently referred to involves walking fast to try to absorb a delay or confront an emergency. These observations provide a partial explanation for worker difficulties in systematically applying certain recommendations based on common sense (e.g. "Don't rush") that are aimed at preventing OAMDs.

This paper describes initially the need for, and limits involved in, neutralising the environmental factors in play and subsequently the production-safety arbitrations prompted by the so-called "organisational" OAMD factors referred to in the literature. Some of these arbitrations imply control implementation by the worker performing the task, which is then reflected in his/her displacements or, more generally, in his/her movements that increase exposure to OAMD risk. Focusing on organisational factors allows us to integrate these controls into a set highlighted by a general work organisation model. Such a model indicates areas of similarity between OAMD genesis and other occupational injury geneses.

\section{Neutralising Environmental Factors: A First Step}

Movement disturbance factors may be permanent and visible (floor in poor condition, congestion, difficult access to parts of a machine, etc.) in some work situations and may expose many workers over relatively long periods. This is the case of slippery floors in food processing shops, for example. Such factors, along with "haste", "carelessness" and "awkwardness" are frequently advanced when explaining OAMD occurrence.

Neutralising environmental factors often involves taking action on certain working conditions (installing a slipresistant floor, reconfiguring an access system, etc.). It is commonplace for companies that decide to raise their OAMD-related safety level primarily focus of this type of action. However, in common with instructions designed to change behaviour (e.g. instructions to workers to move carefully from place to place or to adopt a "safe", unhurried displacement, avoiding short-cuts), this action cannot meet the requirements for preventing all OAMDs. Instructions of this type alone in fact disregard other as- pects, which are sometimes more difficult to objectify and control, such as urgency of the situation, fatigue or certain task requirements. As in all Occupational Accidents (OAs), an OAMD will often be caused by a combination of factors, each of which is of different nature. A clearly visible obstacle is never sufficient to cause a trip: it may simply not be taken into account by a worker, when his/her visual attention is absorbed by his/her task during a displacement. On the other hand, an OAMD can occur without involving a permanent, visible anomaly in the environment: a worker, late for his/her appointment, misses a step when running up stairs that are not subject to any design defect. Finally, many situations are temporarily more susceptible to OAMD occurrence: for example, when performing his/her activity, a worker collides with an element in his/ her environment, which obstructs his/her movement; he/ she had intended to move this element on completion of priority work. In the situation illustrated by Fig. 1a, a first level of prevention would involve disposing of unwanted material or organising storage areas. At a given moment, presence of elements required for performing a task can also represent an accident factor for a worker or his/her colleague. In Fig. 1b, this would be the cinder blocks left near a mason, but could also be a batten left lying on the ground when stripping formwork, a wheelchair when transferring a patient or a toolbox when conducting maintenance work.

Neutralising accident factors that are permanent and visible in the work environment is important, but analysing the part played by this factor in a more comprehensive accident genesis is in fact just as important. Behaviours adopted in work situations also need to be understood since they often reflect the presence of organisational factors.

\section{OAMD Organisational Factors}

The literature includes in-depth analyses of occupational slips, trips and/or other movement disturbances conducted at various companies. Events leading to injury are integral to the relevant company operation and some are related to production-safety arbitrations referred to long ago in the general occupational accident field. For example, situations described in terms of "recovery" or "momentary co-

\footnotetext{
${ }^{1}$ The notion of organisation is vast and the intention here is to describe neither the features nor the different standpoints from which it is considered (cf. Monteau, 2010). The organisational factors referred to in this paper are those, which refer to the organisational activity undertaken by the company.
} 


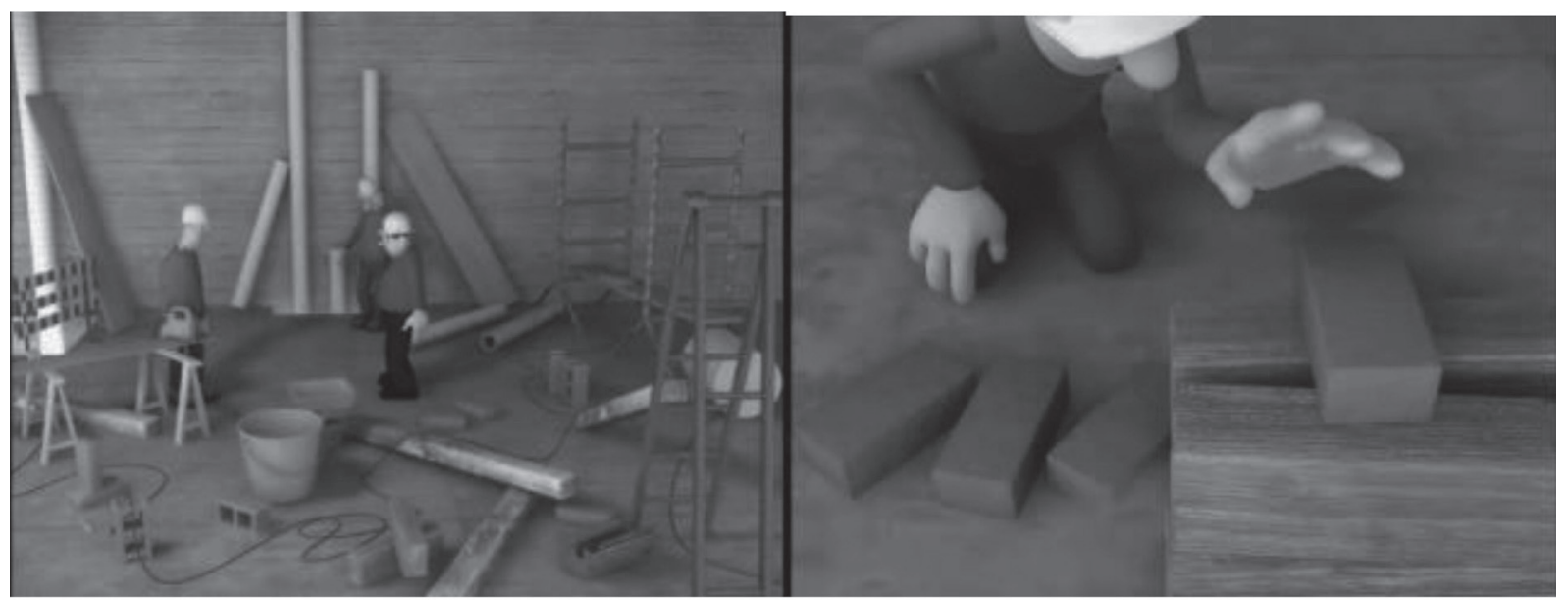

(a)

(b)

Fig. 1. Two images of occupational situations taken from the "Napo in Safe on Site/Champions of the world" video produced by

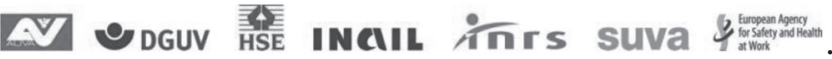

activity" by Faverge ${ }^{10)}$ reflect arbitrations revealed during iron mine accident analysis, in particular. Monteau ${ }^{11}$ refers to "known organisational risks", when analysing occupational health and safety from an organisational perspective. It should be noted that few of these accidentology studies are considered in relation to understanding and preventing OAMDs. Yet, the contribution of multiple organisational factors has been highlighted during analysis of such accidents.

Research reported in Bentley \& Haslam ${ }^{12)}$ and in Leclercq \& Thouy $^{13)}$ questions the role of work preparation in STFA occurrence. Bentley \& Haslam ${ }^{12)}$ effectively describe the difficulties encountered in distributing mail on time during periods involving snow and ice. Leclercq $\&$ Thouy ${ }^{13)}$ show that a number of accidents have involved field operators climbing up into and down from trucks, when checking equipment required during the day at various building sites. This phase of their activity called for all the more care since instances of missing equipment were frequent.

A specific study of OAMDs sustained by train driv$\mathrm{ers}^{14)}$ has revealed problems involving task allocation as well as recovery situations, i.e. situations in which "the normal task is interrupted by an incident, from which the worker has to recover, in other words strive to restore the usual course of work"10). Three train drivers effectively sustained an OAMD within scenarios exhibiting similar characteristics. These accidents occurred when inspecting a train prior to departure: in the first case, the train started to brake during the operation; in the second case, an inexperienced driver detected a brake failure he had never before encountered and did not know how to remedy and, in the third case, the driver once again climbed down from the train because he had overlooked an inspection point. In each case, the driver gave his full attention to inspection in order to prevent the train being delayed and, when walking, tripped on a sleeper or a plate creating unevenness in the ground. In the first two cases, the driver was performing a recovery operation at the time of the accident to restore the train braking system operation. All recovery situations introduce or accentuate a time constraint, so resources mobilised to make the braking system operational as quickly as possible were partially lacking in terms of controlling displacement and this effectively caused the driver to trip.

Bentley et al. ${ }^{15)}$ refer to a "concurrent visual task" when explaining the occurrence of certain OAMDs; these authors also emphasise that, at a given moment, resources dedicated to performing the task may be lacking in terms of controlling displacement.

In many cases, existing obstructions to displacement are due to earlier or simultaneous work performed by workers other than the worker, who sustains an OAMD; this reveals the part played by co-activity or a succession of activities in OAMD occurrence. For example, a worker has to divert to avoid tools useful to other workers installing new equipment, but left on his/her displacement route. Displacement diversion may be considered as a form of recovery activity intended to restore a normal course of work by returning to the initial route. Co-activity, histori- 
cally described by Cuny ${ }^{16)}$, represents task performance by persons pursuing different production objectives and required to share concurrently a common workplace. Interim situations or those involving subcontracted work, in particular, can generate co-activity or a succession of activities.

Finally, Bentley \& Haslam ${ }^{12)}$ have shown that the "job and finish" policy implemented at the time in the United Kingdom's mail distribution company, which allowed workers to go home as soon as the last mail had been distributed, could encourage workers to take risks by hurrying or taking short-cuts. These authors reported that workers explained that the accident risk raised by reading mail addresses while walking was more acceptable than the time wasted in stopping to read the addresses.

\section{Underlying Worker Controls}

Working conditions (hence movement performance conditions) play a part in OAMD occurrence since they make it more or less difficult to control displacement and, more generally, movement during task performance.

Organisational factors highlighted during OAMD analysis reveal worker arbitration between production and safety in the work situation, in which he/she is exposed to a risk of movement disturbance. Productionsafety arbitrations relate particularly to the organisational activity implemented by the company. Neutralisation of organisational factors therefore requires local and collective management of the OAMD risk to ensure proximity to the company's specific characteristics and to compare existing logics and viewpoints. Bentley \& Haslam $^{12)}$ state that, depending on the workers distributing mail, managers consider performance a priority over safety and that the workers themselves prefer rapid performance to safer performance of their work; their attitudes reflect those of the management in this respect.

As in the presence of any OA risk, controls are implemented to perform the task, while ensuring safety with regard to movement disturbance, in other words while ensuring movement control. This risk may a priori manifest itself through any work-related movement. These can be "job-related gestures", for example in the case of a collision when bolting because the spanner slipped. OAMDs can also involve more atypical movements, such as picking up an object or walking, and in some cases, being cut by an element in the environment or missing a step when running up stairs. Controls implemented in work situations are therefore virtually permanent and the

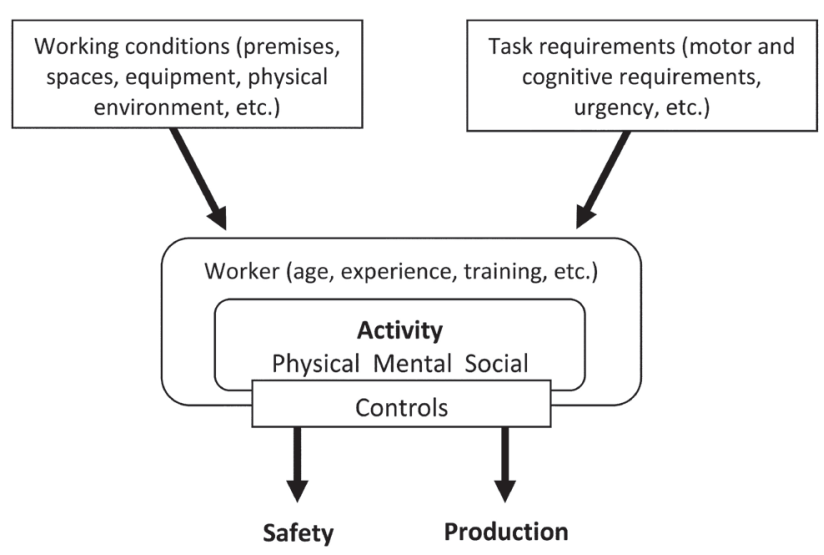

Fig. 2. Model of OSTFA understanding based on the worker and his/ her activity (adapted from the model developed by Vezina (2001) for musculoskeletal disorders).

worker manages the available resources to perform his/her task, while controlling his/her movement. The resources required for movement control vary in time and with respect to the work situation. For example, Derosier et al. ${ }^{17)}$ report situations, in which metallurgists are sometimes required to move over template elements similar to beams. At these moments, the resources required to control their movements are more extensive than those required when walking on a level floor. Likewise, resources required for walking on a floor with variable slip resistance are more extensive than resources required for walking on a surface with uniformly high slip resistance. Resources needed to perform the task as a whole are also variable. At certain moments, a worker's visual attention can be taken up by a task and can thus be unavailable for movement control $^{14,15)}$. Task characteristics and requirements will therefore condition resources, which could be dedicated to movement control.

Figure 2 contributes to our understanding of movement disturbance by illustrating a work situation model based on the worker and his/her activity. This has been adapted from the model developed by Vézina ${ }^{18)}$ in relation to work-related musculoskeletal disorders (WRMSDs). WRMSDs and OAMDs are invariably outcomes of occupational risks, which manifest themselves through worker movements. This is why OAMDs and WRMSDs possess common characteristics with an impact on prevention. OAMD prevention has been the subject of little research to date and could therefore benefit from studies in the WRMSD prevention field, at least from a theoretical and methodological standpoint. This is clearly illustrated by transposing the model developed by Vezina ${ }^{18)}$. Similarities 
between WRMSD and OAMD and their consequences for prevention have been developed by Leclercq et $a l^{4}$.

Figure 2 shows that controls are implemented in work situations to ensure safety when performing a task. Most of these controls have an impact on the movement performed. Movements performed at work are subject to continuous adjustment with respect to the required task and individual, organisational and environmental constraints, as reported by Chassaing ${ }^{19)}$ when studying WRMSDs. Some of the implemented controls can be easily observed (rushing, moving round obstructions, etc.) and the individual strategies, to which these controls contribute, can be examined in detail using personal interviews. Other control mechanisms, often automatically implemented, are harder to grasp. Sometimes, they cannot be visually observed and their detection requires a very fine observation grid: one that accurately describes movements such as heel strike angle when walking, distance provided as a safety margin between the foot and a low-level obstruction during a displacement, supports used, etc.

To acquire a best possible understanding of worker controls implemented to perform a task in an occupational situation, while avoiding movement disturbances, we need to combine two levels of analysis: analysis of the activity and analysis of the movement performed within the activity. These analyses of the same activity are conducted using different observation grids.

\section{Worker Controls within a Set of Controls}

Macroscopic developments such as technological advances or the advent of regulation influence the conditions under which an operator performs his movements and hence the resulting risks present in occupational situations. Figure 3 illustrates a work organisation model developed by the $\mathrm{NIOSH}^{20)}$. Three levels can be distinguished in this representation. The nature of the different factors involved in OA occurrence is displayed, along with the boundaries within which these factors are effectively harmful.

In general, productive organisation characteristics evolve constantly under the specific effects of technical progress (automation, introduction of new technologies, etc.), subsequent growth in productivity ${ }^{21)}$, employment market developments (active population characteristics, etc.) and reorganisations ${ }^{22)}$ (outsourcing, etc.). These macroscopic developments and choices made by productive organisations affect the work situation (level of prescription, time and spatial constraints, etc.) in ways that condition how worker movements are performed.

\section{Organization of Work}

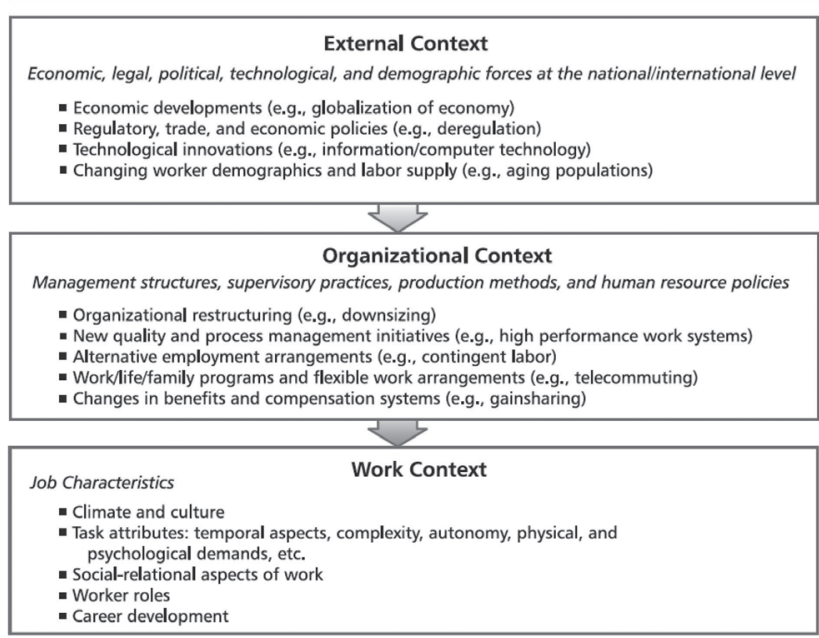

Fig. 3. Organisation of the NIOSH work model taken from Sauter $e t$ al., (2002). This model illustrates the outcome of macroscopic developments in the occupational situation through productive organisation choices.

Controls are continually implemented not only by a worker performing his/her task, while avoiding injuries, but also at the different levels illustrated in Fig. 3. Analysing and combining these controls contributes to our understanding and prevention of occupational accidents, in particular OAMDs.

\section{Conclusion}

Despite scientific progress in the safety field, OAMDs are still commonly considered "simple" accidents resulting from a malfunction in a "simple" system; this might suggest that their prevention is also "simple". This paper aims to encourage changes in these perceptions by attempting to orient the reader's vision towards organisational factors, which often combine with other accident factors to cause movement disturbance and injury in work situations. These risks manifest themselves in the worker's movement but are none the less an unwanted consequence of productive organisational decisions. OAMD organisational factors reveal the need for local and collective management of this risk and the importance of a better understanding of movement/displacement performed under working situations, i.e. in a context integrating specific task requirements and working conditions.

While organisational measures implemented by the company represent a lever for OAMD prevention, two 
points should be noted: on the one hand, organisational activity is restricted as illustrated by Fig. 3 and, on the other hand, its lever is not unique. Maximum possible neutralisation of factors close to the injury in the accident genesis and risk awareness also constitute major lines of prevention. Awareness of the OAMD risk, in particular, is an essential prerequisite to any progress in preventing these accidents. Perception of the OAMD risk and its more or less "accepted" nature are factors, which determine both consideration of this risk at every level of the company and controls implemented by workers.

\section{References}

1) CNAMTS (2012) Statistiques Nationales des accidents du travail, des accidents de trajet et des maladies professionnelles, CNAMTS, Paris.

2) Leclercq S, Monteau M, Cuny X (2009) Occupational accidents with movement disturbance: in support of an operational definition. Proceedings IEA2009 Congress, Pékin, Chine.

3) Leclercq S, Monteau M, Cuny X (2010) Avancée dans la prévention des «chutes de plain-pied » au travail. Proposition de définition opérationnelle d'une nouvelle classe: « les accidents avec perturbation du mouvement (APM). PISTES 12, 16.

4) Leclercq S, Cuny-Guerrier A, Gaudez C, Aublet-Cuvelier A (2014) Proximities between Work Related Musculoskeletal Disorders (WRMSD) and so called Slips, Trips and Falls (STF). Ergonomics.

5) Bell JL, Collins JW, Wolf L, Grönqvist R, Chiou S, Chang WR, Sorock GS, Courtney TK, Lombardi DA, Evanoff B (2008) Evaluation of a comprehensive slip, trip and fall prevention programme for hospital employees. Ergonomics 51, 1906-25. [Medline] [CrossRef]

6) Amandus H, Bell J, Tiesman H, Biddle E (2012) The epidemiology of slips, trips, and falls in a helicopter manufacturing plant. Hum Factors 54, 387-95. [Medline] [CrossRef]

7) Leamon TB, Murphy PL (1995) Occupational slips and falls: more than a trivial problem. Ergonomics 38, 487-98. [Medline] [CrossRef]

8) Davis PR (1983) Human factors contributing to slips, trips and falls. Ergonomics 26, 51-9. [Medline] [CrossRef]

9) Gauchard G, Chau N, Mur JM, Perrin P (2001) Falls and working individuals: role of extrinsic and intrinsic factors. Ergonomics 44, 1330-9. [Medline] [CrossRef]

10) Faverge JM (1970) L'homme agent d'infiabilité et de fiabilité du processus industriel. Ergonomics 13, 301-27. [Medline]

11) Monteau (2010) L'organisation délétère — La santé et la sécurité au travail au prisme de l'organisation, L'Harmattan, Paris.

12) Bentley TA, Haslam RA (1998) Slip, trip and fall accidents occurring during the delivery of mail. Ergonomics 41, 1859-72. [Medline] [CrossRef]

13) Leclercq S, Thouy S (2004) Systemic analysis of socalled 'accidents on the level' in a multi trade company. Ergonomics 47, 1282-300. [Medline] [CrossRef]

14) Leclercq S, Thouy S, Rossignol E (2007) Progress in understanding processes underlying occupational accidents on the level based on case studies. Ergonomics 50, 59-79. [Medline] [CrossRef]

15) Bentley T, Tappin D, Moore D, Legg S, Ashby L, Parker $R$ (2005) Investigating slips, trips and falls in the New Zealand dairy farming sector. Ergonomics 48, 1008-19. [Medline] [CrossRef]

16) CECA (1969) Recherche communautaire sur la sécurité dans les mines et la sidérurgie. Etude de physiologie et de psychologie du travail $\mathrm{N}^{\circ} 4$, CECA, Luxembourg.

17) Derosier C, Leclercq S, Rabardel P, Langa P (2008) Studying work practices: a key factor in understanding accidents on the level triggered by a balance disturbance. Ergonomics 51, 1926-43. [Medline] [CrossRef]

18) Vézina N (2001) La pratique de l'ergonomie face aux TMS: ouverture à l'interdisciplinarité. Proceedings of the SELFACE 2001 Conference - Ergonomics for changing work, SELF, Montreal.

19) Chassaing K (2010) Les "gestuelles" à l'épreuve de l'organisation du travail: du contexte de l'industrie automobile à celui du génie civil. Understanding gesture and work organization: an analysis in the context of the car industry and civil engineering. Trav Hum 73, 163-92. [CrossRef]

20) Sauter SL, Brightwell WS, Colligan MJ, Hurrel JJ Jr, Katz TM, LeGrande DE, Lessin N, Lippin RA, Lipscomb JA, Murphy LR, Peters RH, Keita GP, Robertson SR, Stellman JM, Swanson NG, Tetrick LE (2002) The Changing Organization of Work and the Safety and Health of Working People. Publication No. 2002-116, DHHS (NIOSH), Cincinnati.

21) Wilpert B (2009) Impact of globalization on human work. Saf Sci 47, 727-32. [CrossRef]

22) Op de Beeck R, van Heuverswyn K (2002) New trends in accident prevention due to the changing world. Report from European agency for Safety and Health at Work, Bilbao. http://osha.europa.eu/en/publications/reports/208. Accessed June 24, 2011. 